\title{
Impact of antibiotic therapy in severe community-acquired pneumonia: Data from the Infauci study
}

\author{
J.M. Pereira a,b,c,* ${ }^{\text {J. Gonçalves-Pereira }}{ }^{\text {d,h }}$, O. Ribeiro ${ }^{\text {e }}$, J.P. Baptista ${ }^{\text {f }}$, F. Froes ${ }^{\text {g }}$, J.A. Paiva a,b,c \\ a Emergency and Intensive Care Department, Centro Hospitalar S. João, Porto, Portugal \\ b Department of Medicine, University of Porto Medical School, Porto, Portugal \\ c Grupo de Infecção e Sepsis, Portugal \\ d Intensive Care Unit, Hospital Vila Franca de Xira, Vila Franca de Xira, Portugal \\ e Department of Health Information and Decision Sciences, Center for Research in Health Technologies and Information Systems, CINTESIS, University of Porto Medical School, Porto, Portugal \\ ${ }^{\mathrm{f}}$ Intensive Care Service, Centro Hospitalar e Universitário de Coimbra, Coimbra, Portugal \\ ${ }^{g}$ Intensive Care Unit, Hospital Pulido Valente, Centro Hospitalar Lisboa Norte, Lisboa, Portugal

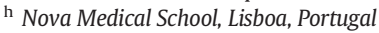

\section{A R T I C L E I N F O}

Available online $\mathrm{xxxx}$

Keywords:

Antibiotic therapy

Severe community-acquired pneumonia

Critically ill

Mortality

Outcome

\begin{abstract}
A B S T R A C T
Antibiotic therapy (AT) is the cornerstone of the management of severe community-acquired pneumonia (CAP). However, the best treatment strategy is far from being established.

To evaluate the impact of different aspects of AT on the outcome of critically ill patients with CAP, we performed a post hoc analysis of all CAP patients enrolled in a prospective, observational, multicentre study.

Of the 502 patients included, $76 \%$ received combination therapy, mainly a $\beta$-lactam with a macrolide ( $80 \%)$. AT was inappropriate in $16 \%$ of all microbiologically documented CAP $(n=177)$. Hospital and 6 months mortality were $34 \%$ and $35 \%$. In adjusted multivariate logistic regression analysis, combination AT with a macrolide was independently associated with a reduction in hospital (OR 0.17,95\%CI 0.06-0.51) and 6 months (OR 0.21, 95\%CI 0.07-0.57) mortality. Prolonged AT ( $>7$ days) was associated with a longer ICU ( 14 vs. 7 days; $p<0.001)$ and hospital length of stay (LOS) (25 vs. 17 days; $\mathrm{p}<0.001$ ).

Combination AT with a macrolide may be the most suitable AT strategy to improve both short and long term outcome of severe CAP patients. AT $>7$ days had no survival benefit and was associated with a longer LOS.
\end{abstract}

(c) 2017 Published by Elsevier Inc.

\section{Introduction}

Community-acquired pneumonia (CAP), described in 1892 as the "Captain of the men of Death" by Sir William Osler [1], represents a major cause of morbidity, mortality and healthcare costs [2-4]. It remains one of the leading causes of hospital admission and 5-15\% of the hospitalized patients will be admitted to an Intensive Care Unit (ICU) [5], largely owing to complications such as shock or respiratory failure.

Abbreviations: CAP, community-acquired pneumonia; $\mathrm{CI}$, confidence interval; $\mathrm{CT}$, computed tomography; ICU, intensive care unit; INFAUCI, infection on admission to the ICU; LOS, length of stay; OR, odds ratio; PSI, pneumonia severity index; RCT, randomized controlled trial; SCAP, severe community-acquired pneumonia; SOFA, sequential organ failure assessment.

* Corresponding author at: Emergency and Intensive Care Department, Centro Hospitalar São João EPE, Department of Medicine, University of Porto Medical School, Porto, Portugal, Grupo de Infecção e Sepsis, Al Prof Hernâni Monteiro, 4200-319 Porto, Portugal.

E-mail address: jmcrpereira@yahoo.com (J.M. Pereira).
Severe community-acquired pneumonia (SCAP) is undoubtedly a life threatening infection with a mortality rate around 30\% [6]. Antibiotic therapy is definitely the cornerstone of its treatment but the best antibiotic strategy has not been established yet. The combination of a macrolide or a "respiratory" fluoroquinolone with a $\beta$-lactam, is advocated by international guidelines [7-9]. Those who seem to benefit most from this combination therapy are patients with bacteremic pneumococcal pneumonia [10-12], septic shock [13] and invasive mechanical ventilation [14]. However controversy persists since this recommendation is supported mostly by retrospective and observational nonrandomized studies [10-12,15,16]. Furthermore, empiric use of combination therapy to all patients with SCAP may lead to antibiotic overuse and consequently to the emergence of antimicrobial resistance in addition to increased risk for Clostridium difficile associated diarrhea and adverse drug events.

The aim of this study was to evaluate the impact of different features of antibiotic therapy (timing, mono vs combination therapy, macrolide use, appropriateness and duration) on short (hospital) and long term (6 months) outcome of SCAP patients admitted to the ICU. 


\section{Materials and methods}

\subsection{Study design and data collection}

The Infection on Admission to the ICU (INFAUCI) study was a prospective, observational, cohort, multicentre study [17]. The study protocol was described elsewhere [17]. Briefly all adult patients (age $\geq 18$ years) consecutively admitted during one year to one of the 14 Portuguese participating units were included and followed until death or 6 months after ICU admission. The Hospital Research and Ethics Committee of Centro Hospitalar S. João approved the study design. Infections and sepsis criteria were identified at the time of admission to the ICU according to commonly used definitions [18]. For the purpose of this study, we analysed data from patients with SCAP at ICU admission. CAP diagnosis was based on the presence of suggestive clinical features (e.g. cough, fever, sputum production, pleuritic chest pain) and a demonstrable new infiltrate on chest radiograph or CT scan [19]. It was classified as severe if it required ICU admission, mainly due to the need of vasopressor support or invasive mechanical ventilation. Patients with pulmonary tuberculosis $(n=7)$ or without available antibiotic therapy data ( $n=27)$ were excluded from the analysis.

Microbiologic evaluation was performed on a local basis and antibiotic therapy was prescribed according to the attending physician. In microbiologically documented infections, antibiotic therapy was considered appropriate if all isolated microorganisms had in vitro sensitivity to at least one of the prescribed antimicrobials. Antibiotics that Pseudomonas aeruginosa has not intrinsic resistance were classified as antipseudomonal antibiotics.

Our primary outcome was short (hospital) and long term mortality (6 months), both in the overall population and in the subset of patients with septic shock. In addition, we also evaluated the impact of antibiotic therapy in ICU and hospital length of stay (LOS). Six months mortality was defined as death by any cause within this time frame counted from ICU admission. LOS was calculated among patients alive at least after 7 days of starting antibiotic therapy and was defined as the number of days from ICU admission to the date of either ICU or hospital discharge.

\subsection{Statistical analysis}

Categorical variables were described as counts and percentages and continuous variables were expressed as median (percentile (P) 5 - P 95) or mean \pm standard deviation according to data distribution. Comparisons between groups were performed with the unpaired Student's $t$ test, Mann-Whitney $U$ test or Kruskal-Wallis for continuous variables and Chi-square test and Fisher's exact test for categorical variables, as appropriate.

The associations between antibiotic therapy and patient's outcome were assessed by odds ratio (OR) with 95\% confidence interval (CI) estimated by logistic regression, adjusted for all relevant variables.

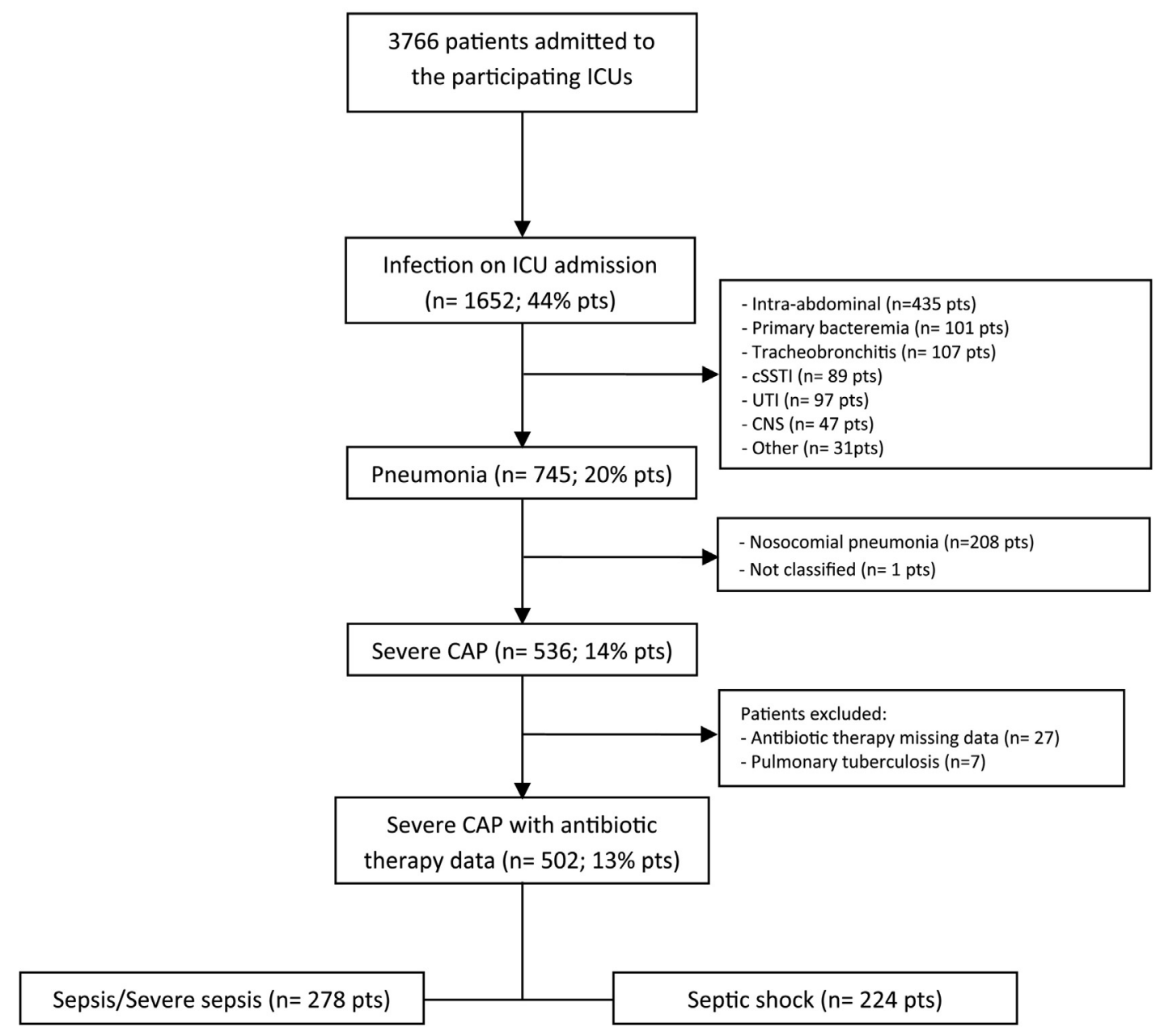

* CAP - Community-acquired pneumonia; cSSTI- Complicated skin and soft tissue infection; UTI- Urinary tract infection; CNS - Central nervous system infection 
Data were analysed using IBM SPSS Statistics v.21.0 (IBM, Somers, NY, USA). All statistics were two-tailed and the significance level was defined as $\mathrm{p}<0.05$.

\section{Results}

\subsection{Patient characteristics}

A total of 3766 consecutive patients were included in the INFAUCI study. Infection on ICU admission was present in $44 \%$, including 536 admitted with SCAP (14.2\%). The final study population consisted of 502 patients with SCAP who had antibiotic therapy data available (Fig. 1).

Most of the patients (66\%) were male with a mean age of $58 \pm$ 17 years and a Simplified Acute Physiology Score II (SAPS II) score of $46 \pm 18$. On the day of ICU admission, the mean Sequential Organ Failure Assessment (SOFA) score and lactate were respectively $9 \pm 4$ and $3.0 \pm 3.1 \mathrm{mmol} / \mathrm{l}$. Mean ICU and hospital LOS were $14 \pm 13$ and $25 \pm$ 22 days, respectively. Hospital and 6-months mortality were, respectively, 34\% and 35\% (Table 1).

SCAP was microbiologically documented in $35 \%$ of the episodes ( $n$ $=177$ ) with secondary bacteremia being present in 54 cases (11\%). Although Streptococcus pneumoniae was the most frequent isolated pathogen $(n=50 ; 10 \%)$, Gram negative bacteria were responsible for $15.5 \%$ of the cases $(n=78)$. Viral pneumonia was documented in $7.4 \%$ ( $n=$ 37) (Table 2). Polymicrobial cases represented $11 \%$ of all microbiological documented SCAP. Forty percent of the patients had some kind of immunosuppression. In $15 \%$ of them, co-infection of bacteria plus influenza virus was observed. Enterobacteriaceae (50\%) and Staphylococcus aureus (40\%) were the most frequent pathogens isolated in polymicrobial pneumonia.

\subsection{Antibiotic treatment}

Most of the patients ( $n=381 ; 76 \%$ ) received combination antibiotic therapy, mainly a $\beta$-lactam plus a macrolide (80\%). In one third of the

Table 1

Baseline characteristics ( $n=502$ patients).

\begin{tabular}{|c|c|}
\hline & $\mathrm{n}=502$ \\
\hline Age, mean (sd) & $58(17)$ \\
\hline Male, $\mathrm{n}(\%)$ & $332(66)$ \\
\hline SAPS II, mean (sd) & $46(18)$ \\
\hline \multicolumn{2}{|l|}{ Functional status, n(\%) } \\
\hline Bedridden & $11(2)$ \\
\hline Independent & $448(89)$ \\
\hline Limited activity & $43(9)$ \\
\hline Co-morbidity, n(\%) & $348(70)$ \\
\hline Alchoolism & $73(15)$ \\
\hline Diabetes Mellitus & $106(21)$ \\
\hline Chronic Hepatic Disease & $33(7)$ \\
\hline Neurologic Disease & $55(11)$ \\
\hline HIV/AIDS & $22(4)$ \\
\hline Chronic Heart Failure & $56(11)$ \\
\hline Imunossupression & $41(8)$ \\
\hline Chronic Renal Failure & $30(6)$ \\
\hline Chronic Respiratory Failure & $90(18)$ \\
\hline Cancer & $52(10)$ \\
\hline Drug Addiction & $14(3)$ \\
\hline Total SOFA, mean (sd) & $9(4)$ \\
\hline Septic Shock, n(\%) & $224(45)$ \\
\hline Lactate $(\mathrm{mmol} / \mathrm{l})$, mean $(\mathrm{sd})$ & $3.03(3.07)$ \\
\hline Microbiological documentation, n(\%) & $177(35)$ \\
\hline Monomicrobial, n(\%) & $157(89)$ \\
\hline Secondary bacteremia, n(\%) & $54(11)$ \\
\hline \multicolumn{2}{|l|}{ Length of stay, mean (sd) } \\
\hline ICU & $14(13)$ \\
\hline Hospital & $25(22)$ \\
\hline \multicolumn{2}{|l|}{ Mortality, n(\%) } \\
\hline Hospital & $172(34)$ \\
\hline 6 Months & $178(35)$ \\
\hline
\end{tabular}

Table 2

Etiology of SCAP ( $n=502$ episodes).

\begin{tabular}{lll}
\hline Microrganisms & & $\mathrm{n}=(\%)$ \\
\hline Gram positive & & $79(15.7)$ \\
& Streptococcus pneumoniae & $50(10)$ \\
& Staphylococcus aureus & $28(5.6)$ \\
Gram negative & Other Streptococcus spp. & $1(0.2)$ \\
& & $78(15.5)$ \\
& Pseudomonas spp. & $16(3.2)$ \\
& E. coli & $15(3.2)$ \\
& Klebsiella spp. & $12(2.4)$ \\
& Haemophilus influenza & $12(2.4)$ \\
& Enterobacter spp. & $7(1.4)$ \\
& Proteus spp. & $4(0.8)$ \\
& Legionella pneumophila & $3(0.6)$ \\
& Acinetobacter spp. & $3(0.6)$ \\
Virus & Serratia spp. & $2(0.4)$ \\
& Moraxella catarrhalis & $2(0.4)$ \\
Other microrganisms & Other Gram negative & $2(0.4)$ \\
& & $37(7.4)$ \\
& H1N1 & $36(7.2)$ \\
& Other virus & $1(0.2)$ \\
& & $8(1.6)$ \\
\hline
\end{tabular}

patients, an antipseudomonal antibiotic was used. The empiric antimicrobial treatment was inappropriate in $16 \%$ of all microbiologically documented cases.

Data on timing to antibiotic first dose was only available in $174 \mathrm{pa}-$ tients (35\%). 83\% of the patients received the first dose in the first $6 \mathrm{~h}$ after hospital admission but only $38 \%$ of patients received it within the first hour (Table 3).

\subsection{Antibiotic treatment and mortality}

Although hospital mortality was similar in patients treated with antibiotic monotherapy or with combination therapy (37\% vs. 33\%; $p=$ 0.43 ), it was significantly lower when a combination therapy including a $\beta$-lactam and a macrolide was used ( $27 \%$ vs. $58 \%$ for all other antibiotic regimens; $\mathrm{p}<0.001$ ). Likewise, hospital mortality was also lower when the initial empiric antibiotic regimen was appropriate (30\% vs. $56 \%$; $\mathrm{p}=$ 0.01 ), but it was higher either when an antibiotic with antipseudomonal activity was empirically used ( $48 \%$ vs. $28 \%$; $p<0.001$ ) or if timing to antibiotic first dose was $\leq 1 \mathrm{~h}$ ( $41 \%$ vs. $25 \% ; p=0.03$ ). No significant difference in hospital mortality was observed between patients that received 7 days or less of appropriate antibiotic therapy and those treated for a longer period ( $23 \%$ vs. $28 \%$; $p=0.39$ ). Similar results were observed when 6 months mortality was used as outcome variable, instead of hospital mortality (Table 3).

In a multivariate logistic regression analysis, age (OR 1.04; 95\%CI 1.01-1.08), SOFA score (OR 1.26; 95\%CI 1.05-1.50), inappropriate empiric antibiotic therapy (OR 6.83; 95\%CI 1.43-32.57) and lactate on admission (OR 1.13; 95\%CI 1.00-1.32) were all independently associated with hospital mortality. On the contrary, the use of combination therapy including a macrolide proved to be protector (OR 0.19; $95 \% \mathrm{CI} 0.06-$ 0.61). Age (OR 1.04; 95\%CI 1.01-1.07) and SOFA score (OR 1.22; 95\%CI 1.04-1.43) remained associated with mortality at 6 months whilst combination therapy including a macrolide persisted protective (OR 0.24 ; $95 \% \mathrm{CI} 0.08-0.69$ ) (Table 4). These results were not influenced by the presence of any kind of immunodeficiency and its presence was not associated with both short (OR 1.76; 95\%CI 0.61-5.04) and long term mortality (OR 1.66; 95\%CI 0.62-4.41) (data not shown).

\subsection{Antibiotic treatment and length of stay}

Combination therapy was associated with a marginally longer median ICU LOS than monotherapy [10 (P5-95: 2-40) vs. 9 (P5-95: 2-43) days; $\mathrm{p}=0.05$ ] but no differences were found between the two groups regarding hospital LOS [19 (P5-95: 3-70) vs. 18 (P5-95: 2-63) days; p 
Table 3

Antibiotic strategies and Hospital and 6 months mortality.

\begin{tabular}{|c|c|c|c|c|c|c|c|c|}
\hline & \multicolumn{4}{|c|}{ Hospital mortality } & \multicolumn{4}{|c|}{6 Months mortality } \\
\hline & Total & Survivor & Non-Survivor & $\mathrm{p}=$ & Total & Survivor & Non-Survivor & $\mathrm{p}=$ \\
\hline $\begin{array}{l}\text { Antibiotic appropriateness } \\
(n=152)\end{array}$ & & & & 0.01 & & & & 0.03 \\
\hline Appropriate & $127(84)$ & $89(70)$ & $38(30)$ & & $127(84)$ & $85(67)$ & $42(33)$ & \\
\hline Inappropriate & $25(16)$ & $11(44)$ & $14(56)$ & & $25(16)$ & $11(44)$ & $14(56)$ & \\
\hline $\begin{array}{l}\text { Number of antibiotics } \\
(n=502)\end{array}$ & & & & 0.43 & & & & 0.65 \\
\hline Monotherapy & $121(24)$ & $76(63)$ & $45(37)$ & & $121(24)$ & $76(63)$ & $45(37)$ & \\
\hline Combination therapy & $381(76)$ & $254(67)$ & $127(33)$ & & $381(76)$ & $248(65)$ & $133(35)$ & \\
\hline $\begin{array}{l}\text { Combination of antibiotics } \\
(\mathrm{n}=381)\end{array}$ & & & & $<0.001$ & & & & $<0.001$ \\
\hline With a Macrolide & 305 & $222(73)$ & $83(27)$ & & 305 & $217(71)$ & $88(29)$ & \\
\hline Without a Macrolide & 76 & $32(42)$ & $44(58)$ & & 76 & $31(41)$ & $45(59)$ & \\
\hline $\begin{array}{l}\text { Anti-pseudomonal antibiotic } \\
(\mathrm{n}=502)\end{array}$ & & & & $<0.001$ & & & & $<0.001$ \\
\hline Yes & $161(32)$ & $84(52)$ & $77(48)$ & & $161(32)$ & $82(51)$ & 79 (49) & \\
\hline No & $341(68)$ & $246(72)$ & $95(28)$ & & $341(68)$ & $242(71)$ & $99(29)$ & \\
\hline $\begin{array}{l}\text { Timing to antibiotic first dose } \\
(n=174)\end{array}$ & & & & 0.03 & & & & 0.04 \\
\hline$\leq 1 \mathrm{~h}$ & $66(38)$ & 39 (59) & $27(41)$ & & $66(38)$ & $39(59)$ & $27(41)$ & \\
\hline$>1 \mathrm{~h}$ & $108(62)$ & $81(75)$ & $27(25)$ & & $108(62)$ & $80(74)$ & $28(26)$ & \\
\hline $\begin{array}{l}\text { Duration of adequate antibiotic therapy } \\
(n=339)\end{array}$ & & & & 0.39 & & & & 0.46 \\
\hline$\leq 7$ days & $134(40)$ & $103(77)$ & $31(23)$ & & $134(40)$ & $101(75)$ & $33(25)$ & \\
\hline$>7$ days & $205(60)$ & $147(72)$ & $58(28)$ & & $205(60)$ & $147(72)$ & $58(28)$ & \\
\hline
\end{tabular}

$=0.12$ ]. Median ICU [10 (P5-95: 2-40) vs. 9 (P5-95: 2-29) days; $\mathrm{p}=$ 0.08 ] and hospital [20 (P5-95: 3-71) vs. 18 (P5-95: 2-65) days; $\mathrm{p}=$ $0.2]$ LOS were similar whether combination therapy included or not a macrolide. Neither appropriate antibiotic therapy nor empiric use of an antipseudomonal antibiotic had impact on ICU and hospital LOS. Patients that received antibiotic therapy for $>7$ days had a longer median ICU [14 (P5-95: 3-48) vs. 7 (P5-95: 2-27) days; $\mathrm{p}<0.001$ ] and hospital [25 (P5-95: 10-83) vs. 17 (P5-95: 6-59) days; $\mathrm{p}<0.001$ ] LOS. (Table 5).

\subsection{Antibiotic treatment and septic shock patients}

Combination therapy by itself was again not associated with a survival benefit in the sub-group of septic shock patients (hospital mortality of $43 \%$ vs. $41 \%$; $=0.82$ ). Nevertheless, when this combination included a macrolide, hospital mortality was also significantly lower ( $35 \%$ vs. 68\%; p < 0.001). On the opposite, regimens that included an antipseudomonal antibiotic were associated with higher hospital mortality ( $63 \%$ vs. $32 \%$; p $<0.001)$.

Table 4

Logistic regression analysis for Hospital and 6 Months mortality $(n=115)$.

\begin{tabular}{|c|c|c|c|c|}
\hline & \multicolumn{2}{|c|}{ Hospital mortality } & \multicolumn{2}{|c|}{$\begin{array}{l}6 \text { Months } \\
\text { mortality }\end{array}$} \\
\hline & OR & $95 \% \mathrm{CI}$ & OR & $95 \% \mathrm{CI}$ \\
\hline Age & 1.04 & $1.01-1.08$ & 1.04 & $1.01-1.07$ \\
\hline Gender male ${ }^{a}$ & 0.27 & $0.09-0.83$ & 0.45 & $0.16-1.27$ \\
\hline Lactate & 1.13 & $1.00-1.32$ & 1.07 & $0.91-1.24$ \\
\hline SOFA & 1.26 & $1.06-1.50$ & 1.22 & $1.04-1.43$ \\
\hline Independent ${ }^{\mathrm{b}}$ & 0.20 & $0.10-4.18$ & 0.27 & $0.01-5.26$ \\
\hline Limited activity ${ }^{\mathrm{b}}$ & 0.14 & $0.01-4.22$ & 0.27 & $0.01-7.48$ \\
\hline Septic shock ${ }^{\mathrm{c}}$ & 0.40 & $0.11-1.39$ & 0.63 & $0.20-1.95$ \\
\hline No co-morbidities ${ }^{\mathrm{d}}$ & 0.64 & $0.18-2.29$ & 0.99 & $0.32-3.09$ \\
\hline Inappropriate antibiotic therapy ${ }^{\mathrm{e}}$ & 6.83 & $1.43-32.57$ & 3.70 & $0.90-15.19$ \\
\hline Combination therapy with macrolide $\mathrm{f}^{\mathrm{f}}$ & 0.19 & $0.06-0.61$ & 0.24 & $0.08-0.69$ \\
\hline \multicolumn{5}{|l|}{ a vs female. } \\
\hline \multicolumn{5}{|l|}{ b vs bedridden. } \\
\hline \multicolumn{5}{|l|}{ c vs. without septic shock. } \\
\hline \multicolumn{5}{|l|}{ d vs. presence of co-morbidities. } \\
\hline e vs appropriate antibiotic therapy. & & & & \\
\hline
\end{tabular}

Antibiotic therapy was inappropriate in only $10 \%$ of septic shock patients. This was associated with a non-statistically significant higher mortality ( $57 \%$ vs. $35 \%$; $p=0.41$ ). In $25 \%$ of these patients ( $n=20$ ), antibiotic therapy was started within $1 \mathrm{~h}$ after hospital admission and this was associated with higher hospital mortality ( $60 \%$ vs. $28 \%$; $p=0.02)$. A longer course of antibiotic therapy ( $>7$ days) provided no survival benefit (Table 6). The effect of these antibiotic strategies on mortality persisted after 6 months (Table 6).

In a logistic regression analysis, combination therapy with a macrolide was the only independently variable that proved to be protective against both hospital (OR 0.09; 95\%Cl 0.02-0.52) and 6 months mortality (OR 0.16 ; 95\% CI 0.03-0.75) in SCAP patients with septic shock. Lactate on admission was independently associated with hospital mortality (OR 1.11; 95\%CI 1.00-1.37), but not with 6 months mortality, in this subset of patients (Table 7).

\section{Discussion}

The main findings of this study are the following: 1) Globally, combination therapy did not improve survival in this cohort of critically ill patients; 2) However, combination therapy with a macrolide was independently associated with a lower hospital and 6 months mortality, namely in patients with septic shock; 3) Inappropriate empiric antibiotic therapy was independently associated with hospital mortality in the overall population, but this association was not observed in the subset of patients with septic shock on admission to the ICU; 4) Duration of appropriate antibiotic therapy not longer than 7 days was not associated with a worst outcome nor increased ICU or hospital LOS; 5) Lactate concentration on ICU admission was an independent risk factor for hospital mortality.

One of the controversial issues in antibiotic therapy for SCAP is the potential advantage of combination therapy. Data to support the recommendation of international guidelines to use combination therapy is coming mainly from non-randomized and retrospective studies [7,8] and randomized controlled trials (RCTs) are lacking.

Recently, Gattarello et al. observed a significant increase in ICU survival when combination antibiotic therapy was used, both in pneumococcal (OR 0.19; 95\% CI: 0.07-0.51) [20] and in non-pneumococcal SCAP (OR 0.23; 95\%CI 0.07-0.74) [21]. On the opposite, in a large RCT of CAP patients this benefit was not observed, even in the most severe 
Table 5

Antibiotic strategies and ICU and Hospital LOS.

\begin{tabular}{|c|c|c|c|c|c|c|c|c|}
\hline & \multicolumn{4}{|c|}{ ICU Length of Stay } & \multicolumn{4}{|c|}{ Hospital Length of Stay } \\
\hline & $\mathrm{n}=$ & Median & P05-P95 & $\mathrm{p}=$ & $\mathrm{n}=$ & Median & P05-P95 & $\mathrm{p}=$ \\
\hline Appropriateness & & & & 0.87 & & & & 0.46 \\
\hline Appropriate & 126 & 10 & $2-40$ & & 121 & 22 & $2-87$ & \\
\hline Inappropriate & 25 & 11 & $2-33$ & & 25 & 20 & $3-57$ & \\
\hline Number of antibiotics & & & & 0.05 & & & & 0.12 \\
\hline Monotherapy & 118 & 9 & $2-43$ & & 117 & 18 & $2-63$ & \\
\hline Combination therapy & 376 & 10 & $2-40$ & & 368 & 19 & $3-70$ & \\
\hline Combination of antibiotics & & & & 0.08 & & & & 0.20 \\
\hline With a Macrolide & 74 & 9 & $2-40$ & & 73 & 18 & $2-63$ & \\
\hline Without a Macrolide & 302 & 10 & $2-38$ & & 295 & 20 & $3-71$ & \\
\hline Anti-pseudomonal antibiotic & & & & 0.18 & & & & 0.82 \\
\hline No & 337 & 10 & $2-40$ & & 331 & 19 & $3-72$ & \\
\hline Yes & 157 & 9 & $2-38$ & & 154 & 20 & $2-63$ & \\
\hline Timing to antibiotic first dose & & & & 0.20 & & & & 0.03 \\
\hline$\leq 1 \mathrm{~h}$ & 65 & 9 & $2-37$ & & 65 & 14 & $2-53$ & \\
\hline$>1 \mathrm{~h}$ & 104 & 10 & $1-38$ & & 101 & 18 & $3-73$ & \\
\hline Duration of adequate antibiotic therapy & & & & $<0.001$ & & & & $<0.001$ \\
\hline$\leq 7$ days & 133 & 7 & $2-27$ & & 130 & 17 & $6-59$ & \\
\hline$>7$ days & 204 & 14 & $3-48$ & & 199 & 25 & $10-83$ & \\
\hline
\end{tabular}

episodes (PSI class V or CURB > 2), although those patients were not admitted to the ICU [22].

Similarly, no difference in 60-day mortality was also found by Adrie et al. between patients receiving dual and monotherapy (Hazards Ratio $1.14 ; 95 \%$ CI: $0.86-1.50 ; p=0.37$ ), even when the analysis was restricted to pneumococcal pneumonia, to microbiologically documented CAP or to patients with septic shock [23]. Likewise, we did not find a clear mortality benefit of combination therapy as a whole in our cohort.

Whether the administration of a specific antibiotic combination is associated with a better outcome in SCAP patients is still not clear. Despite the fact that a benefit from combination therapy is mostly seen when macrolides are part of the antibiotic regimen $[13,14]$, those studies are mostly observational and retrospective and no firm recommendation is given in international guidelines $[7,8]$.

New data has recently been published regarding this issue. A large systematic review and meta-analysis of almost 10,000 critically ill patients with SCAP revealed that macrolide combination therapy was associated with a marginally significant lower mortality compared with non-macrolide therapies ( $21 \%$ vs $23 \%$; Relative Risk 0.84 95\%CI 0.71 1.00 ) [24]. However, when the same analysis was restricted to prospective studies or to patients with either septic shock or invasive mechanical ventilation, no benefit was found. In another observational study of pneumococcal CAP, the authors reported a non-significant decrease in mortality in SCAP cases when a $\beta$-lactam plus macrolide combination was used (Hazards Ratio 0.67; 95\% CI 0.37-1.25) [25]. More recently, no significant differences in mortality were observed between a $\beta$-lactam-macrolide and a $\beta$-lactam-quinolone regimen in ICU patients with non-pneumococcal SCAP [21]. The benefit of combination antibiotic therapy may be more consistent in the more severe sub-group of patients, as proposed by Rodriguez et al. [13], who found, in another observational study, that in CAP patients the benefit of combination therapy was restricted to septic shock patients (Hazards Ratio for monotherapy 2.69; 95\%CI 1.09-2.6). This was consistent with findings in another large cohort of septic shock patients where the early use of combination antibiotic therapy, namely a $\beta$-lactam in combination with an aminoglycoside, a fluoroquinolone or a macrolide, was associated with improved survival [26].

In our study, the use of a combination antibiotic therapy that included a macrolide was independently associated with a significant reduction in hospital (OR 0.19; 95\%CI 0.06-0.61) and 6 months (OR 0.24; 95\%CI 0.08-0.69) mortality. The same benefit was noted when the analysis was restricted to the specific cohort of patients with septic shock.

Inadequate empirical antibiotic treatment was independently associated with hospital mortality in septic patients admitted to the ICU with "nonsurgical" sepsis (OR 8.14; 95\% CI 1.98-33.5) [27] and a fivefold reduction in survival (OR 8.99; 95\% CI: 6.60-12.23) in septic shock patients [28]. Regarding SCAP, few studies specifically evaluated the impact of antibiotic inappropriateness. Falagas et al., in a systematic

Table 6

Antibiotic strategies in septic shock patients and mortality.

\begin{tabular}{|c|c|c|c|c|c|c|}
\hline & \multicolumn{3}{|c|}{ Hospital mortality } & \multicolumn{3}{|c|}{6 months mortality } \\
\hline & Survivor & Non-survivor & $\mathrm{p}=$ & Survivor & Non-survivor & $\mathrm{p}=$ \\
\hline Appropriateness $(n=73)$ & & & 0.41 & & & 0.44 \\
\hline Appropriate & $43(65)$ & $23(35)$ & & $40(61)$ & $26(39)$ & \\
\hline Inappropriate & $3(43)$ & $4(57)$ & & $3(43)$ & $4(57)$ & \\
\hline Number of antibiotics $(n=224)$ & & & 0.82 & & & 0.62 \\
\hline Monotherapy & $26(59)$ & $18(41)$ & & $26(59)$ & $18(41)$ & \\
\hline Combination therapy & $103(57)$ & $77(43)$ & & $99(55)$ & $81(45)$ & \\
\hline Combination of antibiotics $(n=180)$ & & & $<0.001$ & & & 0.001 \\
\hline With a Macrolide & $90(65)$ & $49(35)$ & & $86(62)$ & $53(38)$ & \\
\hline Without a Macrolide & $13(32)$ & $28(68)$ & & $13(32)$ & $28(68)$ & \\
\hline Anti-pseudomonal antibiotic $(\mathrm{n}=224)$ & & & $<0.001$ & & & $<0.001$ \\
\hline Yes & $28(37)$ & $48(63)$ & & $27(36)$ & $49(64)$ & \\
\hline No & $101(68)$ & $47(32)$ & & $98(66)$ & $50(34)$ & \\
\hline Timing to antibiotic first dose $(n=80)$ & & & 0.02 & & & 0.02 \\
\hline$\leq 1 \mathrm{~h}$ & $8(40)$ & $12(60)$ & & $8(40)$ & $12(60)$ & \\
\hline$>1 \mathrm{~h}$ & $43(72)$ & $17(28)$ & & $42(70)$ & $18(30)$ & \\
\hline Duration of adequate antibiotic therapy $(n=127)$ & & & 0.45 & & & 0.32 \\
\hline$\leq 7$ days & $29(67)$ & $14(33)$ & & $27(63)$ & $16(37)$ & \\
\hline$>7$ days & $62(74)$ & $22(26)$ & & $60(71)$ & $24(29)$ & \\
\hline
\end{tabular}


Table 7

Logistic regression analysis for hospital and 6 months mortality in septic shock patients $(n=61)$

\begin{tabular}{|c|c|c|c|c|}
\hline & \multicolumn{2}{|c|}{ Hospital mortality } & \multicolumn{2}{|c|}{6 months mortality } \\
\hline & OR & $95 \% \mathrm{CI}$ & OR & $95 \% \mathrm{CI}$ \\
\hline Age & 1.02 & $0.97-1.07$ & 1.02 & $0.98-1.06$ \\
\hline Gender male $\mathrm{a}^{\mathrm{a}}$ & 0.44 & $0.08-2.49$ & 1.03 & $0.22-4.88$ \\
\hline Lactate & 1.11 & $1.00-1.37$ & 1.03 & $0.85-1.25$ \\
\hline SOFA & 1.22 & $0.94-1.57$ & 1.22 & $0.96-1.55$ \\
\hline No co-morbidities ${ }^{\mathrm{b}}$ & 0.26 & $0.02-2.92$ & 1.33 & $0.24-7.49$ \\
\hline Inappropriate antibiotic therapy ${ }^{c}$ & 4.20 & $0.33-53.48$ & 1.44 & $0.17-12.12$ \\
\hline Combination therapy with macrolide ${ }^{\mathrm{d}}$ & 0.09 & $0.02-0.52$ & 0.16 & $0.03-0.75$ \\
\hline \multicolumn{5}{|l|}{ a vs female. } \\
\hline \multicolumn{5}{|l|}{ b vs. Presence of co-morbidities. } \\
\hline \multicolumn{5}{|l|}{ c vs appropriate antibiotic therapy. } \\
\hline
\end{tabular}

review of 2 RCT and 4 prospective studies addressing pneumococcal pneumonia, did not observe a statistically significant difference in mortality ( 19 vs. $21 \%$; $p=0.66$ ) or clinical success ( 88 vs. $83 \%$; $p=0.57$ ) between appropriate and inappropriate antibiotic [29]. Similar results were noted in a prospective, observational study of 844 patients with pneumococcal bacteremia, a high mortality rate irrespective of the appropriateness of antibiotic therapy [10]. On the opposite, a recent multicentre observational cohort French study suggested that initial adequate antibiotic therapy was associated with a better survival (Hazards Ratio 0.63; 95\% CI: 0.42-0.94) in SCAP patients, namely in patients with septic shock [23]. However, in this study, initial antibiotic therapy was considered adequate if at least one antibiotic was active in vitro against the isolated pathogen or, in the non-microbiologically documented SCAP, if treatment was in accordance with current guidelines, although this can be misleading. In our study, despite the low rate of microbiological documentation, there was an association between initial appropriate antibiotic therapy and survival. Yet, in our logistic regression model, this association was only verified with hospital but not with long term mortality. In the subgroup of patients with septic shock, we did not identify association between inappropriate initial antibiotic therapy with either short or long term mortality (Tables 4 and 7).

According to international guidelines [7,8], an antipseudomonal antibiotic should be prescribed whenever risk factors for Pseudomonas aeruginosa are present. Interestingly, we observed significantly higher hospital mortality in those patients that received an antipseudomonal antibiotic. We can hypothesize that this could have resulted from higher toxicity, worse coverage of gram positive bacteria with some drugs (e.g., ceftazidime) and higher rate of nosocomial infections caused by multidrug resistant microorganisms. Another possible explanation is the use by the attending physician of broad spectrum antibiotics with anti-pseudomonal activity in the most severe cases of CAP which can be associated with a higher mortality. These results raise the question on which patients should we empirically treat with an antipseudomonal antibiotic. Patients with structural lung abnormalities (e.g., bronchiectasis), severe chronic obstructive pulmonary disease, immunosuppressed and those previous colonized with Pseudomonas aeruginosa are those who probably will benefit from the empiric use of antipseudomonal drug but this needs to be confirmed in future studies.

In a responding patient, both European [8] and American [7] guidelines recommend that treatment duration should generally not exceed 7-8 days, although there are no RCT to support it in SCAP. Indeed little is known about the impact of shortened treatments in critically ill patients. After excluding patients that died in the first 7 days after ICU admission, we found that receiving 7 days or less of adequate antibiotic treatment did not led to higher short or long term mortality rate but was associated with a slightly shorter ICU and hospital LOS. Our data are consistent with other published studies. Recently, Uranga et al. [30], in a multicentre RCT, including 39\% of patients with SCAP (PSI classes IV-V), showed that shorter duration of therapy (median 5 days) was not associated with higher in-hospital mortality or longer hospital LOS. The same was noted by Choudhury et al. [31], in a prospective observational study of SCAP patients (CURB score 3-5): no difference in 30-day mortality between short ( 7 days) or longer ( $>7$ days) antibiotic regimens. However patients admitted to the ICU were excluded in both studies.

Serum lactate is a well-known prognostic marker in septic patients. It has been associated with short term mortality in severe septic patients independently of organ dysfunction or shock [32]. In CAP its prognostic role is not well documented. Gwak et al. observed that in hospitalized CAP patients, including $18 \%$ admitted to the ICU, initial serum lactate concentration was independently associated with in-hospital mortality (aOR1.24; 95\%CI 1.01-1.53) [33]. In our specific cohort of SCAP patients, initial serum lactate was associated with hospital mortality (OR 1.13; 95\%CI 1.00-1.32), namely in patients with septic shock (OR $1.11 ; 95 \%$ CI 1.00-1.37), but not with long term mortality.

Some strengths of our study deserve to be highlighted: the large number of critically ill patients with SCAP (almost half with septic shock) prospectively included and the different aspects of antibiotic therapy that were simultaneously addressed.

However, several limitations also merit consideration. Firstly, and most importantly, this was an observational study and unknown bias may have influenced the results. Secondly, we did not use any pneumonia specific score to assess severity, although these scores have been shown to be more useful to identify low-risk patients that can be safely discharged. We also did not collect data regarding the use of adjuvant therapies, namely corticosteroids, which could impact on outcome. Lack of data regarding intubation rate and duration of mechanical ventilation are also limitations that should be stated. Nevertheless, mean respiratory SOFA score on ICU admission was 3, showing that a large proportion of patients received invasive mechanical ventilation. Bacterial load and the virulence of the microorganisms were other variables that were not collected and could have impacted outcome.

\section{Conclusions}

In SCAP patients, the only antibiotic strategy that seems to improve significantly both hospital and 6 months mortality is the use of combination of antibiotics that includes a macrolide. Appropriate empiric antibiotic therapy improved short term survival (but not in the subgroup of patients with septic shock). Courses of appropriate antibiotic therapy longer than 7 days are not associated with a survival benefit but may lead to longer ICU and hospital LOS. Serum lactate showed to be a good prognostic marker of hospital mortality.

\section{Declarations}

\section{Ethical approval and consent to participate}

The Hospital Research and Ethics Committee of Centro Hospitalar S. João approved the study design which has therefore been performed in accordance with ethical standards laid down in the 1964 Declaration of Helsinki and its later amendments. Informed consent was waived due to the observational nature of the study.

\section{Consent for publication}

Not applicable.

\section{Availability of supporting data}

OR takes responsibility for archiving the data.

\section{Competing interests}

None of the authors have any competing interests in the manuscript. 


\section{Authors' contributions}

JG-P, JMP, JPB, FF and J-AP conceived the study, participated in its design and coordination and served as the steering committee. J-AP acted as chair of the steering committee. JMP reviewed the database, and checked for implausible values and inconsistencies in the data. OR supervised data analysis and takes responsibility for archiving the data. All authors read, contributed and approved the final manuscript.

\section{Acknowledgments}

Members of the INFAUCI study group: Conceição Sousa Dias, José Manuel Pereira, José-Artur Paiva, Serviço Medicina Intensiva, Centro Hospitalar S. João (Porto); Lurdes Santos, Alcina Ferreira, UCI - Doenças Infecciosas, Centro Hospitalar S. João (Porto); Richard Maul, Serviço de Medicina Intensiva, Centro Hospitalar Funchal (Funchal); Vasco Tavares, Ana Josefina Mendes, Serviço de Cuidados Intensivos, Centro Hospitalar Vila Nova Gaia/Espinho (Gaia); Paulo Marçal, Piedade Amaro, Unidade de Cuidados Intensivos Polivalente, Centro Hospitalar Entre Douro e Vouga (Vila da Feira); Anabela Bártolo, Ruth Milheiro, Serviço de Cuidados Intensivos, Centro Hospitalar Alto Ave (Guimarães); Filomena Faria, Serviço de Cuidados Intensivos, Instituto Português de Oncologia-Norte (Porto); João Pedro Baptista, Eduardo Sousa, Serviço de Medicina Intensiva, Hospitais Universidade de Coimbra (Coimbra); Sofia Beirão, Ana Marques, Serviço de Medicina Intensiva, Centro Hospitalar Covões (Coimbra); Eduardo Melo, Unidade de Cuidados Intensivos Polivalente, Hospital São Teotónio (Viseu); João GonçalvesPereira, Joana Silvestre, Unidade de Cuidados Intensivos Polivalente, Hospital S. Francisco Xavier (Lisboa); Filipe Froes, Unidade de Cuidados Intensivos Respiratórios, Centro Hospitalar Lisboa Norte (Lisboa); Maria João Vilas, Unidade de Cuidados Intensivos, Hospital do Litoral Alentejano (Santiago do Cacém); José Vaz, Unidade de Cuidados Intensivos, Hospital José Joaquim Fernandes (Beja); Luís Bento, Unidade de Cuidados Intensivos Polivalente 2, Centro Hospitalar de Lisboa Central (Lisboa); Orquídea Ribeiro, Faculdade de Medicina da Universidade do Porto (Porto).

\section{Financial support}

This work was supported by an unrestricted grant from GIS (Grupo de Infecção e Sepsis, Porto, Portugal).

\section{References}

[1] Osler $W$. The principles and practice of medicine. Designed for the use of practitioners and students of medicine. New York: D. Appleton and Company; 1892

[2] Fine MJ, SM, Carson CA, Mutha SS, Sankey SS, Weissfeld LA, et al. Prognosis and outcomes of patients with community-acquired pneumonia: a meta-analysis. JAMA 1996;275(2):134-41.

[3] Bauer TT, WT, Ernen C, Schlosser BM, Thate-Waschke I, de Zeeuw J, et al. Cost analyses of community-acquired pneumonia from the hospital perspective. Chest 2005; 128(4):2238-46

[4] Colice GL, MM, Asche C, Birnbaum HG. Treatment Costs of Community-acquired Pneumonia in an Employed Population, 125; 2004 2140-5(6).

[5] Chalmers JD, MP, Singanayagam A, Akram AR, Choudhury G, Short PM, et al. Severity assessment tools to guide ICU admission in community-acquired pneumonia: systematic review and meta-analysis. Intensive Care Med 2011;37(9):1409-20.

[6] Brito V, NM. How Does One Diagnose and Manage Severe Community-acquired Pneumonia? Evidence-based Practice of Critical Care; 2011 253-62

[7] Mandell LA, WR, Anzueto A. Infectious Disease Society of American/American Thoracic Society consensus guidelines for the management of community acquired pneumonia in adults. Clin Infect Dis 2007;44:S27-72.

[8] Woodhead M, BF, Ewig S, Garau J, Huchon G, Ieven M, et al. Guidelines for the management of adult lower respiratory tract infections- full version. Clin Microbiol Infect 2011;17(Suppl6):E1-59.
[9] Lim WS, BS, George RC, Hill AT, Jamieson C, Le Jeune I, et al. BTS guidelines for the management of community acquired pneumonia in adults: update 2009. Thorax 2009;64(Suppl. 3):iii1-55.

[10] Baddour LM, YV, Klugman KP, Feldman C, Ortqvist A, Rello J, et al. Combination antibiotic therapy lowers mortality among severely ill patients with pneumococcal bacteremia. Am J Respir Crit Care Med 2004;170(4):440-4.

[11] Waterer GW, SG, Wunderink RG. Monotherapy may be suboptimal for severe bacteremic pneumococcal pneumonia. Arch Intern Med 2001:161:1837-42.

[12] Martínez JA, HJ, Almela M, Marco F, Soriano A, García E, et al. Addition of a macrolide to a beta-lactam-based empirical antibiotic regimen is associated with lower in-hospital mortality for patients with bacteremic pneumococcal pneumonia. Clin Infect Dis 2003:36(4):389-95.

[13] Rodríguez A, MA, Sirvent JM, Barcenilla F, de la Torre-Prados MV, Solé-Violán J, et al. Combination antibiotic therapy improves survival in patients with community-acquired pneumonia and shock. Crit Care Med 2007;35(6):1493-8.

[14] Martin-Loeches I, LT, Rodriguez A, Putensen C, Annane D, Garnacho-Montero J, et al. Combination antibiotic therapy with macrolides improves survival in intubated patients with community-acquired pneumonia. Intensive Care Med 2010;36(4): 612-20.

[15] Mufson MA, SR. Bacteremic pneumococcal pneumonia in one American City: a 20year longitudinal study, 1978-1997. Am J Med 1999;107(1A):34S-43S.

[16] Weiss K, LD, Cortes L, Beaupre A, Gauthier R, Gregoire P, et al. Clinical characteristics at initial presentation and impact of dual therapy on the outcome of bacteremic Streptococcus pneumoniae pneumonia in adults. Can Respir J 2004;11(8):589-93.

[17] Gonçalves-Pereira J, PJ, Ribeiro O, Baptista JP, Froes F, Paiva JA. Impact of infection on admission and of the process of care on mortality of patients admitted to the Intensive Care Unit: the INFAUCI study. Clin Microbiol Infect 2014;20(12):1308-15.

[18] Levy MM, FM, Marshall JC. SCCM/ESICM/ACCP/ATS/SIS International Sepsis Definitions Conference. Crit Care Med 2003;2003(31):1250-6.

[19] File Jr TM, MT. Burden of community-acquired pneumonia in north American adults. Postgrad Med 2010;122:130-41.

[20] Gattarello S, BB, Solé-Violán J, Vallés J, Vidaur L, Zaragoza R, et al. Decrease in mortality in severe community-acquired pneumococcal pneumonia: impact of improving antibiotic strategies (2000-2013). Chest 2014;146(1):22-31.

[21] Gattarello S, LL, Vidaur L, Solé-Violán J, Zaragoza R, Vallés J, et al. Improvement of antibiotic therapy and ICU survival in severe non-pneumococcal community-acquired pneumonia: a matched case-control study. Crit Care 2015:19.

[22] Postma DF, VWC, van Elden LJ, Thijsen SF, Hoepelman AI, Kluytmans JA, et al. Antibiotic treatment strategies for community-acquired pneumonia in adults. $\mathrm{N}$ Engl J Med 2015;372(14):1312-23.

[23] Adrie C, SC, Garrouste-Orgeas M, Vignoud L, Planquette B, Azoulay E, et al. Initial use of one or two antibiotics for critically ill patients with community-acquired pneumonia: impact on survival and bacterial resistance. Crit Care 2013;17.

[24] Sligl WI, AL, Eurich DT, Tjosvold L, Marrie TJ, Majumdar SR. Macrolides and mortality in critically ill patients with community-acquired pneumonia: a systematic review and meta-analysis. Crit Care Med 2014;42(2):420-32.

[25] Aspa J, RO, Rodriguez de Castro F, Huertas MC, Borderías L, Cabello FJ, et al. Impact of initial antibiotic choice on mortality from pneumococcal pneumonia. Eur Respir J 2006;27(5):1010-9.

[26] Kumar A, ZR, Light B, Parrillo J, Maki D, Simon D, et al. Early combination antibiotic therapy yields improved survival compared with monotherapy in septic shock: a propensity-matched analysis. Crit Care Med 2010;38(9):1773-85.

[27] Garnacho-Montero J, G.-G.J, Barrero-Almodovar A, Jimenez-Jimenez FJ, PerezParedes C, Ortiz-Leyba C. Impact of adequate empirical antibiotic therapy on the outcome of patients admitted to the intensive care unit with sepsis. Crit Care Med 2003;31(12):2742-51.

[28] Kumar A, EP, Arabi Y, Roberts D, Light B, Parrillo JE, et al. Initiation of inappropriate antimicrobial therapy results in a fivefold reduction of survival in human septic shock. Chest 2009;136(5):1237-48.

[29] Falagas ME, SI, Bliziotis IA, Panos GZ. Impact of initial discordant treatment with beta-lactam antibiotics on clinical outcomes in adults with pneumococcal pneumonia: a systematic review. Mayo Clin Proc 2006;81(12):1567-74.

[30] Uranga A, EP, Bilbao A, Quintana JM, Arriaga I, Intxausti M, et al. Duration of antibiotic treatment in community-acquired pneumonia: a multicenter randomized clinical trial. JAMA Intern Med 2016;176(9):1257-65

[31] Choudhury G, MP, Singanayagam A, Akram AR, Chalmers JD, Hill AT. Seven-day antibiotic courses have similar efficacy to prolonged courses in severe community-acquired pneumonia - a propensity-adjusted analysis. Clin Microbiol Infect 2011; 17(12):1852-8.

[32] Mikkelsen ME, MA, Gaieski DF, Goyal M, Fuchs BD, Shah CV, et al. Serum lactate is associated with mortality in severe sepsis independent of organ failure and shock. Crit Care Med 2009;37(5):1670-7

[33] Gwak MH, JS, Jeong T, Lee JB, Jin YH, Yoon J, et al. Initial serum lactate level is associated with inpatient mortality in patients with community-acquired pneumonia. Am J Emerg Med 2015;33(5):685-90. 